\title{
Aplicação da ferramenta FMEA em uma empresa de injeção de plástico
}

Silas Almeida Lira (Autarquia Educacional do Belo jardim) E-mail: silas_al@hotmail.com

João Victor Cavalcanti Alves (Autarquia Educacional do Belo jardim) E-mail: jcavalcanti900@gmail.com

Josemir Soares de Araújo (Autarquia Educacional do Belo jardim) E-mail: josemirsoares.9@gmail.com

Raul José Rosendo Santos (Autarquia Educacional do Belo jardim) E-mail: raulj2@outlook.com

Armando Dias Duarte (Autarquia Educacional do Belo jardim) E-mail: armando01.dias@gmail.com

\section{Resumo}

O presente trabalho apresenta a aplicação da metodologia Failure Mode and Effect Analysis (FMEA), como ferramenta de classificação de riscos em processos industriais em uma empresa de injeção na cidade do Belo Jardim. Foram elaborados FMEA's para todos os produtos produzidos na fábrica, separando-os por família e buscando-se identificar possíveis falhas e mecanismos potenciais. Em seguida, foram estudados os efeitos e a classificação de risco de cada etapa do processo. Após a elaboração do FMEA, foi identificado que a etapa do processo, verificar nível do silo da injetora, apresenta um elevado Número de Prioridade de Risco (NPR), no qual foram realizadas duas ações, cujos indicadores de desempenho ao longo de onze meses, demonstraram uma mudança significativa para a organização, após a implantação do FMEA.

Palavras-Chaves: FMEA, NPR, Qualidade.

\section{Introdução}

Através da literatura é possível encontrar várias definições para o desenvolvimento da gestão da qualidade em seus diferentes ramos (LONGO, 1996; GOMES, 2004, AVELINO, 2005). Garvin (2002) comenta que a qualidade pode ser abordada de diversas maneiras, podendo ser de forma transcendental, baseada no produto, no usuário, na produção ou no valor.

Campos et al. (2005) exemplifica que no pós-guerra o Japão se encontrava em uma situação de vulnerabilidade, devido à falta de recursos naturais e embargos econômicos, o que fez com que para contornar a situação, foi investido em ferramentas de gerenciamento com o cunho de melhoria nos quesitos de qualidade. 
Devido as exigências do mercado, com consumidores cada vez mais exigentes, uma Gestão da Qualidade Total (GQT) dentro das organizações, deverá garantir uma maior confiabilidade durante os processos produtivos, de forma a reduzir os índices de defeitos de fabricação. No contexto empresarial, há a necessidade de implementar a GQT através das normas como a NBR ISO 9001 devido as exigências do mercado. A NBR 5462 (1994) adota o termo de Análise dos Modos de Falha e seus efeitos, cujo termo em inglês Failure Mode and Effects Analysis (FMEA), representa uma análise qualitativa do estudo de modos de falhas e determinação dos efeitos (ABNT, 1994).

Segundo Billing (2012) a qualidade dos produtos e serviços comercializados, certificados pelas normas proporcionam a empresa um diferencial competitivo, contribuindo para a busca de novos negócios e para a manutenção dos existentes. Por tanto torna-se evidente a necessidade de desenvolver um sistema que atenda aos requisitos e se adeque aos objetivos organizacionais estabelecidos para a prospecção da empresa no mercado.

Nesse contexto, o objetivo deste estudo foi a elaboração do FMEA no processo de fabricação em uma empresa, na cidade do Belo Jardim-PE que atua na produção de peças plásticas.

\section{Referencial teórico}

Cada FMEA deve assegurar que seja dada atenção a cada item do produto ou montagem, componentes ou processos críticos e relacionados à segurança, que devem receber atenção prioritária. É uma ferramenta preventiva que busca antecipar o evento ou acontecimento, e para ter um impacto ainda maior o mesmo deve ser elaborado na etapa de projeto de um produto ou processo no qual exista o potencial de modo de falha. A elaboração ainda na fase de projeto facilita a implementação de modificações de produto ou processo e com menor custo, minimizando as crises de alterações tardias. As ações geradas de um FMEA podem reduzir ou eliminar a possibilidade de erros que possam gerar problemas ainda maiores (MOURA, 2000).

Em geral, é aplicado a falhas potenciais, nos processos de concepção e fabricação de produtos, quando os benefícios são claros e potencialmente significativos. Existem quatro clientes que devem ser considerados no processo de FMEA: 
a) usuário final - a pessoa ou organização que utilizará o produto;

b) montagem e centros de fabricação - onde ocorre as operações de fabricação (processos posteriores);

c) fabricação em cadeia de suprimentos - local de fabricação da peça;

d) reguladores - agências governamentais.

O FMEA é um documento vivo e deve ser revisado sempre que houver alterações de projeto ou processo, outro ponto é que deve ser definido uma revisão periódica para classificação da Ocorrência e Detecção.

A Figura 1 a seguir, demonstra um modelo de formulário de como é realizado a sua elaboração.

Figura 1 - Modelo do formulário adotado

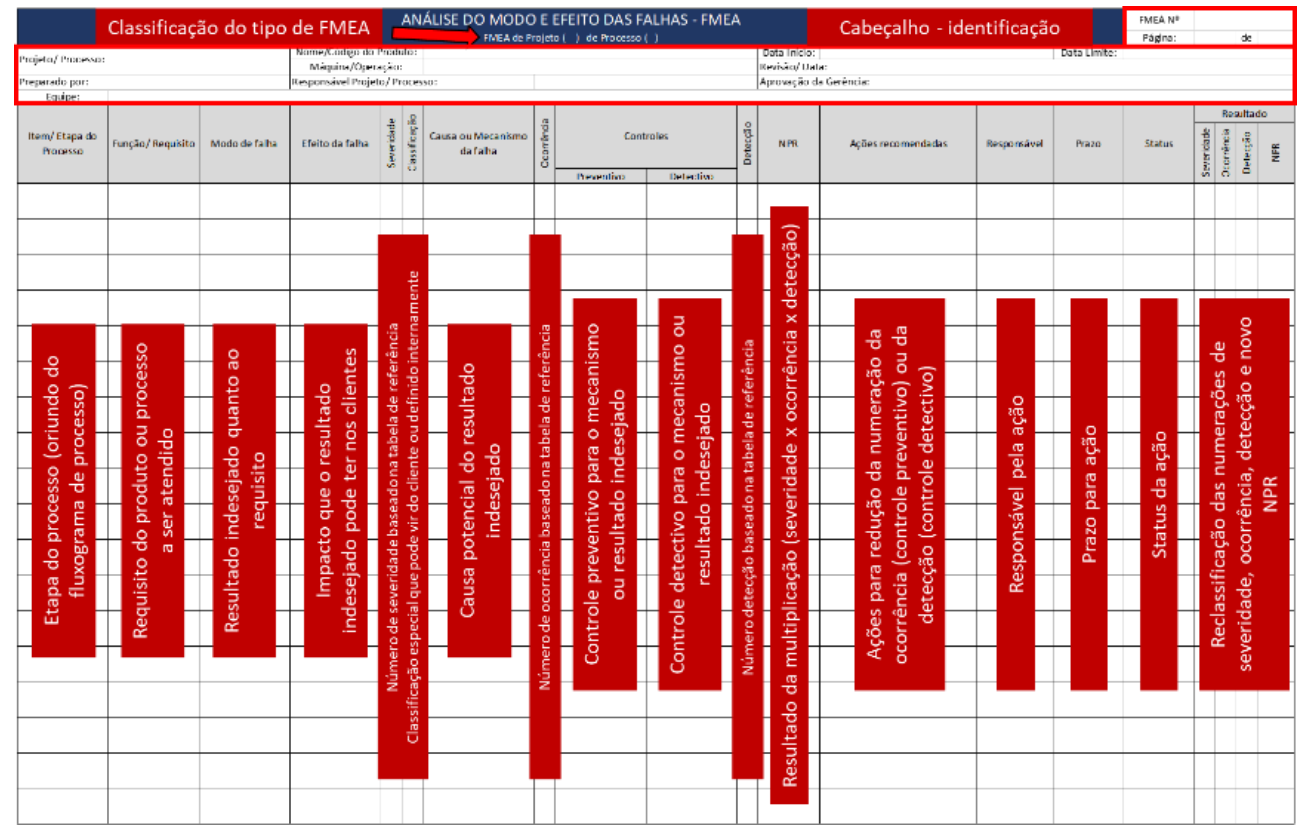

Fonte: Autores (2019)

Conforme Moura (2000), após a conclusão do preenchimento do FMEA é necessário definir esforços/ações adicionais para reduzir o risco. Devido a limitação de recursos, tempo, tecnologia entre outros fatores, deve-se escolher a melhor forma de priorização desses esforços. 
O foco inicial deve ser referenciado para os modos de falha com severidade 9 ou 10, é fundamental que o risco seja tratado com controles de projeto ou ações conforme documentadas no FMEA.

Para modos de falha com severidade de 8 ou inferiores, deve-se considerar as maiores classificações de ocorrência ou detecção. Uma abordagem para auxiliar na priorização é usar o Número de Prioridade de Risco (NPR), descrita através da Equação 1. Os valores do FMEA podem variar de 1 a 1000 .

$$
\text { NPR = Severidade }(S) \text { x Ocorrência }(O) \text { x Detecção (D) }
$$

O manual do FMEA $4^{\circ}$ edição não recomenda o estabelecimento de um valor limite de NPR, pois um processo com severidade 9 ou 10 pode ter uma ocorrência baixa enquanto um processo com severidade 8 e ocorrência alta pode ser priorizado primeiro.

O FMEA é divido em alguns tipos, os mais utilizados são do DFMEA (FMEA de projeto) e o PFMEA (FMEA de processo). De acordo com Laurenti et al. (2012) o DFMEA tem como foco os modos de falhas causados por deficiências no projeto do produto, enquanto o PFMEA está ligado os processos de fabricação ou montagem. O processo de elaboração do DFMEA deve ser iniciado nas etapas iniciais do projeto, enquanto o PFMEA deve ser elaborado antes de serem desenvolvidos e adquiridos o ferramental ou o equipamento de fabricação.

\section{Metodologia}

O estudo foi desenvolvido em uma empresa que atua no mercado de produção de peças plásticas, que conta com 23 colaboradores, que funciona em 2 turnos de trabalho. Segundo o SEBRAE (2013) a empresa é considerada de Pequeno Porte (EPP), já que possui o número de colaborados dentro da faixa de 20-99, sendo estes os limites inferior e superior para esta categoria industrial, respectivamente, definidos pela entidade de serviço social. Dentre seus processos produtivos, a organização estudada possui o processo de injeção e o processo de acabamento. A elaboração do PFMEA foi realizada através de reuniões com uma equipe multidisciplinar da organização, com representantes dos setores de qualidade, produção e manutenção.

Para o desenvolvimento do FMEA foram elaborados os fluxogramas de processo que são considerados, inputs, junto com requisitos dos clientes, reclamações e indicadores internos. 
Como a empresa não é responsável pelo projeto dos produtos foi elaborado o PFMEA (FMEA de processo).

\section{Resultados e discussão}

Como não foram definidos modos de falha com severidade 9 ou 10, foi criada a Tabela 1 cujas classificações dos processos com maiores incidências de risco são apresentadas.

Tabela 1 - Classificação de risco

\begin{tabular}{|c|c|c|c|c|c|c|}
\hline Processos & Modo de Falha & Mecanismo de falha & Severidade & Ocorrência & Detecção & NPR \\
\hline $\begin{array}{l}\text { INJ02 - } \\
\text { Verificar nível } \\
\text { do silo da } \\
\text { injetora } \\
\end{array}$ & $\begin{array}{l}\text { Nível abaixo de } \\
50 \%\end{array}$ & $\begin{array}{l}\text { Falta de material no } \\
\text { almoxarifado por } \\
\text { problema no } \\
\text { fornecedor }\end{array}$ & 8 & 10 & 7 & 560 \\
\hline \multirow[t]{4}{*}{ INJ05 - Injetar } & Produto arranhado & $\begin{array}{l}\text { Acúmulo de peças no } \\
\text { caixote }\end{array}$ & 7 & 10 & 7 & 490 \\
\hline & $\begin{array}{l}\text { Produto com } \\
\text { empeno }\end{array}$ & $\begin{array}{l}\text { Falha no projeto do } \\
\text { molde }\end{array}$ & 7 & 9 & 7 & 441 \\
\hline & $\begin{array}{l}\text { Produto com } \\
\text { rebarba }\end{array}$ & $\begin{array}{l}\text { Desgaste do molde por } \\
\text { falta de preventiva }\end{array}$ & 5 & 10 & 7 & 350 \\
\hline & $\begin{array}{l}\text { Produto com } \\
\text { manchas de } \\
\text { desmoldante }\end{array}$ & $\begin{array}{l}\text { Problema na extração } \\
\text { da peça por } \\
\text { deficiência no molde }\end{array}$ & 5 & 10 & 7 & 350 \\
\hline $\begin{array}{l}\text { REC03 - Fazer } \\
\text { descarrego do } \\
\text { material }\end{array}$ & $\begin{array}{l}\text { Causar danos ao } \\
\text { material no } \\
\text { descarrego }\end{array}$ & $\begin{array}{l}\text { Bag rasgar no } \\
\text { descarrego }\end{array}$ & 7 & 7 & 7 & 343 \\
\hline $\begin{array}{l}\text { ACA12 - selar } \\
\text { pastilha }\end{array}$ & $\begin{array}{l}\text { Pastilha selada } \\
\text { parcialmente }\end{array}$ & Cabeçote desalinhado & 7 & 7 & 7 & 343 \\
\hline
\end{tabular}

Fonte: Autores (2019)

A etapa/mecanismo de falha com o maior NPR foi o INJ02 - Verificar nível do silo da injetora. Como forma de reduzir o número de ocorrências, foram definidas duas ações, sendo a primeira o aumento da quantidade de material e colocar supervisor como o responsável, tendo um prazo para execução da ação até a data 29/11/2019; já a segunda ação foi a determinação de um estoque de segurança capaz de evitar a falta de material diante da incerteza de ressuprimento, com o responsável pela ação sendo o supervisor e o prazo também para 29/11/2019. 
Figura 2 - Ações recomendadas

\begin{tabular}{|c|c|c|c|c|c|c|c|c|c|c|}
\hline \multirow{2}{*}{$\begin{array}{l}\frac{0}{0} \\
\frac{\pi}{0} \\
\frac{0}{2} \\
\stackrel{0}{2}\end{array}$} & \multirow{2}{*}{ 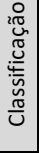 } & \multirow{2}{*}{$\begin{array}{c}\text { Causa ou Mecanismo } \\
\text { da falha }\end{array}$} & \multirow{2}{*}{ 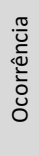 } & \multicolumn{2}{|c|}{ Controles } & \multirow{2}{*}{ 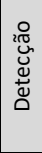 } & \multirow{2}{*}{ NPR } & \multirow{2}{*}{ Ações recomendadas } & \multirow{2}{*}{ Responsável } & \multirow{2}{*}{ Prazo } \\
\hline & & & & Preventivo & Detectivo & & & & & \\
\hline \multirow{3}{*}{8} & \multirow{3}{*}{$\mathrm{HI}$} & $\begin{array}{l}\text { Operador não repor o } \\
\text { material no cilo }\end{array}$ & 2 & - & $\begin{array}{l}\text { Visor de acrílico } \\
\text { do cilo }\end{array}$ & 7 & 112 & & & \\
\hline & & \multirow{2}{*}{$\begin{array}{l}\text { Falta de material no } \\
\text { almoxarifado por } \\
\text { problema no } \\
\text { fornecedor }\end{array}$} & \multirow[b]{2}{*}{10} & \multirow[b]{2}{*}{-} & \multirow[b]{2}{*}{$\begin{array}{l}\text { Monitoramento } \\
\text { do estoque }\end{array}$} & \multirow[b]{2}{*}{7} & \multirow[b]{2}{*}{560} & Aumentar o layout de material & Supervisor & $29 / 11 / 2019$ \\
\hline & & & & & & & & Criar estoque de segurança & Supervisor & $29 / 11 / 2019$ \\
\hline
\end{tabular}

Fonte: Autores (2019)

Foram listadas ao todo 33 ações de melhoria visando a redução do número de ocorrência ou detecção. Até a data da elaboração do trabalho, foram concluídos $27 \%$ das ações levantadas, com impacto de redução de 7,65\% na soma dos NPR's, de 15.029 para 13.882. Como forma de monitorar os impactos da implantação do FMEA foram escolhidos os seguintes indicadores: número de reclamações de clientes e percentual de descarte de produtos (Scrap). Todas as informações estão descritas na Tabela 2:

Tabela 2 - Resultados dos indicadores

\begin{tabular}{ccccccccccccc}
\hline Indicador & $\mathbf{2 0 1 8}$ & Jan & Fev & Mar & Abr & Mai & Jun & Jul & Ago & Set & Out & Nov \\
\hline Scrap & $0,90 \%$ & $0,78 \%$ & $1,02 \%$ & $0,85 \%$ & $0,92 \%$ & $1,05 \%$ & $0,87 \%$ & $0,91 \%$ & $0,42 \%$ & $0,31 \%$ & $0,48 \%$ & $0,37 \%$ \\
\hline $\begin{array}{l}\text { Reclamações } \\
\text { (Acumulado) }\end{array}$ & 18 & 1 & 1 & 1 & 1 & 1 & 1 & 1 & 1 & 1 & 1 & 1 \\
\hline
\end{tabular}

Fonte: Autores (2019)

Conforme visto na Tabela 2 após a elaboração do FMEA no mês de agosto, houve uma redução de $56 \%$ na média do scrap em comparação aos sete primeiros meses do ano. Também se observou que a estabilidade quanto ao número de reclamações no ano se manteve no acumulado de 1, sendo uma redução de 94\% em relação a 2018.

Essa redução é semelhante aos resultados apresentados por Soares et al. (2014) que após a aplicação do FMEA em uma empresa intitulada "Firma", obteve uma redução de $50 \%$ no número de reclamações em 2011 comparado a 2009, de 18\% em 2012 e de $10 \%$ em 2013. Se obteve também uma redução no custo com as reclamações, de 2011 a 2013 houve uma redução de aproximadamente $41 \%$. 
Em outro caso apresentado por Souza (2018) após a aplicação do FMEA em uma empresa de bebidas, obteve uma redução de 6\% no Scrap em relação ao ano de 2016 e um aumento da produtividade em $15 \%$ após a aplicação da ferramenta.

Fontolan et al. (2017) também mostraram que após a aplicação do FMEA em uma empresa de cosméticos, obteve na etapa de purificação um aumento de $8 \%$ no rendimento de produção.

\section{Conclusões}

Baseado nos resultados da aplicação da ferramenta na organização estudada, foi possível identificar os principais processos que apresentam possíveis modos de falhas, e após as ações realizadas, houve uma redução significativa do número de reclamações e do percentual de descarte de produtos, o que corrobora com outros resultados encontrados na literatura. Assim, a ferramenta FMEA se mostrou eficaz, sendo fundamental na priorização e na apresentação de resultados rápidos, de forma a se obter ganhos empresariais.

\section{REFERÊNCIAS}

AVELINO, A. Qualidade no processo de produção: um modelo de gestão para garantira qualidade de acabamento das carrocerias em chapa na linha de produção, Dissertação de Mestrado, Escola Politécnica da Universidade de São Paulo, São Paulo, 2005.

ASSOCIAÇÃO BRASILEIRA DE NORMAS TÉCNICAS - ABNT. NBR 5462:

Confiabilidade e mantenabilidade. ABNT, 1994.

BILLIG, O. A. Sistema de Gestão Integrada de Qualidade, Segurança, Meio-Ambiente e Saúde. Revista Eletrônica FTEC, 2012.

CAMPOS, R. et al. A ferramenta 5S e suas implicações na gestão da qualidade total. Simpep-Simpósio de Engenharia de Produção, 2005.

FONTOLAN, E. et al. Aplicação de FMEA para Análise de riscos e oportunidades no processo de produção de uma indústria de cosméticos. REVISTA UNINGÁ REVIEW, ,32.1: p. 114-124, 2017

GARVIN, D. Gerenciando a qualidade: a visão estratégica e competitiva. Rio de Janeiro: Qualitymark, 2002.

GOMES, P. A. Evolução do conceito de qualidade: dos bens manufaturados aos serviços de informação, Cadernos BAD, vol. 2, pp. 6-18, 2004.

LAURENTI, R. et al. Avaliação da Aplicação dos Métodos FMEA e DRBFM no Processo de Desenvolvimento de Produtos em uma Empresa de Autopeças. Gestão \& Produção, 2012. 
LONGO, R. M. J. Gestão da Qualidade: Evolução Histórica, Conceitos Básicos e Aplicação na Educação. Brasília, 1996.

MAINARDES, E. W.; LOURENÇO, L.; TONTINI, G. Percepções dos Conceitos de Qualidade e Gestão pela Qualidade Total: estudo de caso na universidade. Revista Gestão.Org, 2010.

MOURA, C. Análise de Modo e Efeitos de Falha Potencial (FMEA), Manual de Referência SAE J-1739., ASQC, 2000.

SEBRAE - Serviço Brasileiro de Apoio às Micro e Pequenas Empresas. Anuário do trabalho na micro e pequena empresa: 2013. 6. ed. Departamento Intersindical de Estatística e Estudos Socioeconômicos. Brasília. DIEESE, 2013.

SOARES, T. M. da C. Q., et al. Análise da eficácia da aplicação da Metodologia FMEA do Processo: Caso de estudo numa empresa certificada. 2014.

SOUZA, R. S. de. Aplicação da ferramenta FMEA de processos em uma indústria de bebidas. 2018 . 